Research Article

\title{
Histopathological Changes in Gastric Mucosal Biopsies in Chronic Gastritis and Correlation of Pathological Features with Helicobacter Pylori Infection
}

\author{
Poonam Sharma $^{1 *}$, Kuldeep Kumar Kaul ${ }^{1}$, Manik Mahajan ${ }^{2}$, Vijyant Singh Chandail ${ }^{3}$, Kuldeep Goswami ${ }^{4}$, \\ Puneet Gupta ${ }^{5}$ \\ 1. Department of Pathology, GMC Hospital, Jammu University, Jammu, J\&K, India \\ 2. Department of Radio-diagnosis and Imaging, PGIMS, Pt. B.D. Sharma University of Health Sciences, Rohtak, \\ Haryana, India \\ 3. Department of Medicine, GMC Hospital, Jammu University, Jammu, J\&K, India \\ 4. Department of Pathology, ASCOMS Hospital, Jammu University, Jammu, J\&K, India \\ 5. Department of Radio-diagnosis and Imaging, ASCOMS Hospital, Jammu University, Jammu, J\&K, India.
}

Corresponding Author: Poonam Sharma, 39-A Extension, Gandhi Nagar, Jammu, J\&K, India - 180004, Email: sharmapoonam59@gmail.com

\begin{abstract}
Introduction: Diseases related to gastric acid account for nearly one third of all health expenditure on gastrointestinal (GI) diseases. Evaluation of morphological features in chronic gastritis using updated Sydney system has not been systematically evaluated in India. So this study was done to interpret the histopathological changes in chronic gastritis using updated Sydney system and to correlate these pathological features with Helicobacter pylori (H. pylori) infection. Methods Gastric mucosal biopsies in a tertiary care centre in north India were evaluated using routine histopathological methods. Histopathological changes in patients with chronic gastritis were interpreted using updated Sydney system and correlated with H. pylori infection. Results: Chronic gastritis was seen in 89 cases. Histological grading of chronic gastritis was done by updated Sydney system. Chronic inflammation was present in $100 \%$ cases, neutrophilic activity in $39.33 \%$ cases, intestinal metaplasia in $7.87 \%$ cases, glandular atrophy in $12.36 \%$ cases and lymphoid follicles in $29.21 \%$ cases. H. pylori were identified in $50.56 \%$ cases of chronic gastritis. Association of H. pylori with pathological features in chronic gastritis was evaluated. The association of $\mathrm{H}$. pylori with degree of chronic inflammation, neutrophilic activity and lymphoid aggregates was statistically significant. Conclusions: Histopathology should be performed in all cases of chronic gastritis. The updated Sydney classification provides an objective histological evaluation of chronic gastritis. The grade of chronic inflammation, neutrophilic activity and lymphoid follicles are significantly associated with $\mathrm{H}$. pylori infection. So search for H. pylori should be initiated if neutrophils and lymphoid follicles are seen in the antral biopsies.
\end{abstract}

Key words: Helicobacter pylori, gastritis, dyspepsia, endoscopy

\section{Introduction:}

Disorders of the stomach are a frequent cause of clinical disease, with inflammatory and neoplastic lesions being particularly common. Diseases related to gastric acid account for nearly one third of all health care spending on gastrointestinal (GI) diseases. Symptomatology of gastric diseases range from dyspepsia to altered bowel

Manuscript received: $11^{\text {th }}$ March 2015

Reviewed: $24^{\text {th }}$ March 2015

Author Corrected: $4^{\text {th }}$ April 2015

Accepted for Publication: $19^{\text {th }}$ April 2015 movements and dysphagia to GI bleed. Patients presenting with dyspepsia are often subjected to upper GI endoscopy as the first line of investigation. Endoscopic screening may detect mucosal lesions at an early stage especially atrophy, intestinal metaplasia and dysplasia so as to prevent progress of lesions to invasive cancer [1]. Biopsy sampling of gastric mucosa at diagnostic endoscopy provides information that cannot be obtained by other means. The most common 
indication for gastric biopsy is the need to know whether or not the patient is infected with $\mathrm{H}$. pylori, and whether the stomach is gastritic or not. Microscopic examination of gastric biopsy specimens, in addition to H. pylori status, provides information about the grade, extent, and topography of gastritis-related and atrophyrelated lesions in the stomach. It has been firmly established and known that the endoscopic findings in H. pylori gastritis do not correlate with histological changes. Biopsy provides an excellent opportunity for the clinician and histopathologist to correlate the clinical data, endoscopic findings and pathological lesions. H. pylori infection has been established firmly with the development of peptic ulcer, chronic active gastritis, chronic persistent gastritis, atrophic gastritis and gastric neoplasia including gastric adenocarcinoma and gastric mucosa associated lymphoid tissue lymphomas [2]. The reported prevalence of $\mathrm{H}$. pylori in patients with functional dyspepsia ranges from $39-87 \%$ [3]. It is widely accepted that colonization of the gastric surface epithelium by $\mathrm{H}$. pylori is commonly associated with type B chronic gastritis. H. pylori were seen in $77 \%$ cases of gastritis [4] and $80 \%$ cases of gastric ulcer [5]. The recognition that $\mathrm{H}$. pylori play a pivotal role in the pathogenesis of several gastroduodenal pathologies makes its diagnosis necessary in many different circumstances and therefore investigation for this organism has become an integral part of upper GI endoscopy. To remove confusion in the diagnosis of various forms of gastritis, the Sydney system was introduced to produce a standardized approach to the histological interpretation of gastric biopsies [6]. The Sydney system was later on updated in Houston in 1994 [7] and the histological division of this classification utilized graded variables for evaluation of chronic gastritis. Government Medical College, Jammu is a tertiary care teaching hospital where facilities for diagnosis and treatment of GI diseases exist. The rate of chronic gastritis and H. pylori infection in India is high.

\section{Research Article}

Evaluation of morphological features in chronic gastritis using updated Sydney system and its correlation with $\mathrm{H}$. pylori infection has not been systematically evaluated in India. Hence this prospective study was done to interpret the histopathological changes in chronic gastritis using updated Sydney system and to correlate these pathological features with $\mathrm{H}$. pylori infection.

\section{Materials and Methods:}

This prospective study was conducted in the Department of Pathology, Government Medical College, Jammu over a period of one year $\left(1^{\text {st }}\right.$ November 2012 to $31^{\text {st }}$ October 2013). All biopsies obtained for various symptoms of dyspepsia like abdominal pain, bloating, heartburn, nausea, vomiting and postprandial fullness were included in the study. Exclusion criteria included absolute/relative contraindication to upper GI endoscopy and attempt at H. pylori eradication or acid suppressive therapy in the last 2 weeks. All patients had given informed consent for the study and a local ethics committee had approved the protocol. After overnight fasting, upper GI endoscopy was performed on selected patients using Fujinon EG-265WR fiber-optic gastroscope under local anaesthesia with $10 \%$ xylocaine spray. Gastric mucosal biopsies from body and antrum were taken in each case. The biopsies were then processed, cut into sections of 4 micrometer thickness, stained with Haematoxylin and Eosin (H\&E) and modified Giemsa techniques. The slides were evaluated by two pathologists and morphological variables of chronic gastritis were graded as mild, moderate and severe according to updated Sydney system. The association between histological findings and $H$. pylori infection was assessed by means of chi square test. A probability value of less than 0.05 was considered statistically significant.

\section{Results:}

A total of 100 patients who presented with symptoms of dyspepsia were included in the study. Upper GI endoscopy was performed in all patients and endoscopic mucosal biopsies were taken for histopathological evaluation. All the biopsies with evidence of chronic gastritis were evaluated. The biopsies were analysed taking into consideration the various histological parameters such as chronic inflammatory infiltrate, inflammatory activity, glandular atrophy, intestinal metaplasia, H. pylori and presence of lymphoid follicles. Out of 100 patients, chronic gastritis was seen in $89 \%$ cases (89/100). Majority of cases were seen in the 31-40 years age group followed by 41-50 years age group (Table 1). There were 56 males and 33 female patients with an M: F ratio of 1.7: 1. Histological grading of chronic gastritis was done by updated Sydney system [8] (Table 2). Chronic inflammation was present in $89(100 \%)$ cases of chronic gastritis out of which, $44(49.44 \%)$ had mild, $38(42.70 \%)$ had moderate and 7 (7.87\%) had severe chronic inflammation. Neutrophilic activity was seen in $35(39.33 \%)$ cases of which $22(24.72 \%)$ had mild, $9(10.11 \%)$ had moderate and $4(4.49 \%)$ 
Research Article

had severe neutrophilic activity. Intestinal metaplasia was seen in 7 (7.87\%) cases with 5 cases (5.62\%) having mild and 2 cases $(2.25 \%)$ having moderate intestinal metaplasia. Glandular atrophy was seen in 11 (12.36\%) cases out of which 7 $(7.87 \%)$ were of mild grade and $4(4.49 \%)$ were of moderate grade. Lymphoid follicles and lymphoid collections were seen in $26(29.21 \%)$ cases of chronic gastritis. H. pylori were identified in $45(50.56 \%)$ cases of chronic gastritis on gastric mucosal biopsies. Out of these $45(50.56 \%)$ cases, $23(25.84 \%)$ had mild, 18 (20.22\%) had moderate and 4 (4.49\%) had severe H. pylori colonization (Table 2). Association of H. pylori and degree of inflammation in chronic gastritis was evaluated (Table 3). 16 out of $44(36.36 \%)$ cases of chronic gastritis with mild chronic inflammatory cell infiltrate were positive for $\mathrm{H}$. pylori whereas 23 out of $38(60.53 \%)$ and 6 out of $7(85.71 \%)$ cases of chronic gastritis with moderate and severe chronic inflammation were positive for $\mathrm{H}$. pylori respectively. The association of $\mathrm{H}$. pylori and degree of chronic inflammation was statistically significant ( $\mathrm{p}$ value < 0.05). Further, association of $\mathrm{H}$. pylori with activity, lymphoid aggregates, intestinal metaplasia and atrophy in chronic gastritis was also evaluated (Table 4). 35 cases of chronic gastritis showed activity. 30 of these 35 cases (85.71\%) were positive for H. pylori. The association was statistically significant ( $\mathrm{p}$ value $<0.05$ ). 26 cases of chronic gastritis showed lymphoid aggregates. 20 of these 26 cases (76.92\%) were positive for $\mathrm{H}$. pylori and the association was statistically significant ( $\mathrm{p}$ value $<0.05$ ). 7 cases of chronic gastritis showed intestinal metaplasia and 2 out of these 7 cases (28.57\%) were positive for H. pylori. The association was not statistically significant ( $\mathrm{p}$ value $>0.05$ ). 11 cases of chronic gastritis showed atrophy. 7 out of these 11 cases (63.64\%) were positive for $\mathrm{H}$. pylori and the association was not statistically significant ( $\mathrm{p}$ value $>0.05$ ).

Table 1: Age distribution in chronic gastritis

\begin{tabular}{|c|c|c|}
\hline Age groups (years) & No. of cases & Percentage \% \\
\hline $11-20$ & 4 & 4.49 \\
\hline $21-30$ & 11 & 12.36 \\
\hline $31-40$ & 31 & 34.83 \\
\hline $41-50$ & 25 & 28.09 \\
\hline $51-60$ & 14 & 15.73 \\
\hline $61-70$ & 3 & 3.37 \\
\hline$>70$ & 1 & 1.12 \\
\hline
\end{tabular}

Table 2: Histological grading of chronic gastritis by updated Sydney system

\begin{tabular}{|c|c|c|c|c|c|}
\hline Histological variables & Total & $\%$ & Grade & No. & $\%$ \\
\hline \multirow{3}{*}{ Chronic Inflammation } & \multirow{3}{*}{89} & \multirow{3}{*}{100} & Mild & 44 & 49.44 \\
\hline & & & Moderate & 38 & 42.70 \\
\hline & & & Severe & 7 & 7.87 \\
\hline \multirow{3}{*}{ Activity } & \multirow{3}{*}{35} & \multirow{3}{*}{39.33} & Mild & 22 & 24.72 \\
\hline & & & Moderate & 9 & 10.11 \\
\hline & & & Severe & 4 & 4.49 \\
\hline \multirow{3}{*}{ Intestinal Metaplasia } & \multirow{3}{*}{7} & \multirow{3}{*}{7.87} & Mild & 5 & 5.62 \\
\hline & & & Moderate & 2 & 2.25 \\
\hline & & & Severe & 0 & 0 \\
\hline \multirow{3}{*}{ Atrophy } & \multirow{3}{*}{11} & \multirow{3}{*}{12.36} & Mild & 7 & 7.87 \\
\hline & & & Moderate & 4 & 4.49 \\
\hline & & & Severe & 0 & 0 \\
\hline \multirow{3}{*}{ H. pylori } & \multirow{3}{*}{45} & \multirow{3}{*}{50.56} & Mild & 23 & 25.84 \\
\hline & & & Moderate & 18 & 20.22 \\
\hline & & & Severe & 4 & 4.49 \\
\hline
\end{tabular}


Research Article

Table 3: Association of $\mathrm{H}$. Pylori and degree of chronic inflammation in chronic gastritis

\begin{tabular}{|l|c|c|c|}
\hline Inflammation & No. of Cases & H. pylori positive & Percentage \% \\
\hline Mild & 44 & 16 & 36.36 \\
\hline Moderate & 38 & 23 & 60.53 \\
\hline Severe & 7 & 6 & 85.71 \\
\hline
\end{tabular}

$\mathrm{p}$ Value $<0.05$

Table 4: Association of H. Pylori with activity, lymphoid aggregates, intestinal metaplasia and atrophy in chronic gastritis

\begin{tabular}{|c|c|c|c|l|}
\hline Histological variables & Total cases & H. pylori positive & \% & p Value \\
\hline Activity & 35 & 30 & 85.71 & $<0.0001$ \\
\hline Lymphoid aggregates & 26 & 20 & 76.92 & 0.003 \\
\hline Intestinal metaplasia & 7 & 2 & 28.57 & 0.527 \\
\hline Atrophy & 11 & 7 & 63.64 & 0.543 \\
\hline
\end{tabular}

\section{Discussion:}

Chronic gastritis is a very common condition worldwide. The basic histological alteration is an increase in the chronic inflammatory cells in gastric mucosa. Chronic infection with H. pylori is now believed to account for the majority of cases of chronic gastritis [8].

There are two main mechanisms by which H. pylori may produce inflammation. Firstly, the organism may interact with surface epithelial cells producing either direct cell damage or the liberation of epithelium derived pro-inflammatory mediators. Secondly, H. pylori derived products may gain access to the underlying mucosa, thereby directly stimulating host non-specific and specific immune responses involving the liberation of variety of cytokine messengers [9].

Histopathological evaluation is the gold standard for diagnosis of this organism. In an attempt to remove confusion in the diagnosis of various forms of gastritis, the Sydney system was introduced in 1990 [6]. The Sydney system of grading and classification of gastritis was developed with the aim of producing a standardized approach to the histological interpretation of gastric biopsies. Its importance lies in the potential to maintain a common language among pathologists and to provide clinicopathological correlation [10].

The Sydney system was updated in Houston, Texas in 1994. The histological division of this classification utilizes graded variables which include chronic inflammation, neutrophilic activity, glandular atrophy, intestinal metaplasia and H. pylori density [7].

In the present study, maximum cases of chronic gastritis were seen in 31-40 and 41-50 years age group. A higher incidence was seen in males with an M: F ratio of 1.7: 1. Chen XY et al. [11] also found an M: F ratio of 1.8: 1.Histological grading of chronic gastritis was done by updated Sydney system. Chronic inflammation was present in $100 \%$ cases of chronic gastritis, out of which, $49.44 \%$ had mild, $42.70 \%$ had moderate and $7.87 \%$ had severe chronic inflammation similar to the results of Manxhuka-Kerliu S et al. [12].

Neutrophilic infiltration was seen in $39.33 \%$ cases with $24.72 \%$ patients having mild, $10.11 \%$ moderate and $4.49 \%$ severe neutrophilic activity. Garg B et al. [8] also observed neutrophilic activity in $33.33 \%$ cases of chronic gastritis. 
Research Article

Intestinal metaplasia was seen in 7.87\% cases which is similar to the studies by Garg B et al. [8] and Atisook K et al. [13] who reported intestinal metaplasia in $7 \%$ and $8.2 \%$ cases respectively. Glandular atrophy was seen in $12.36 \%$ cases, out of which $7.87 \%$ had mild grade and $4.49 \%$ had moderate grade of atrophy. Garg B et al. [8], Atisook K et al. [13] and Dhakhwa R et al. [14] reported glandular atrophy in $12.33 \%, 11.6 \%$ and $10 \%$ cases respectively. Lymphoid follicles and lymphoid collections were seen in $29.21 \%$ cases of chronic gastritis in the present study.

\section{Figures:}

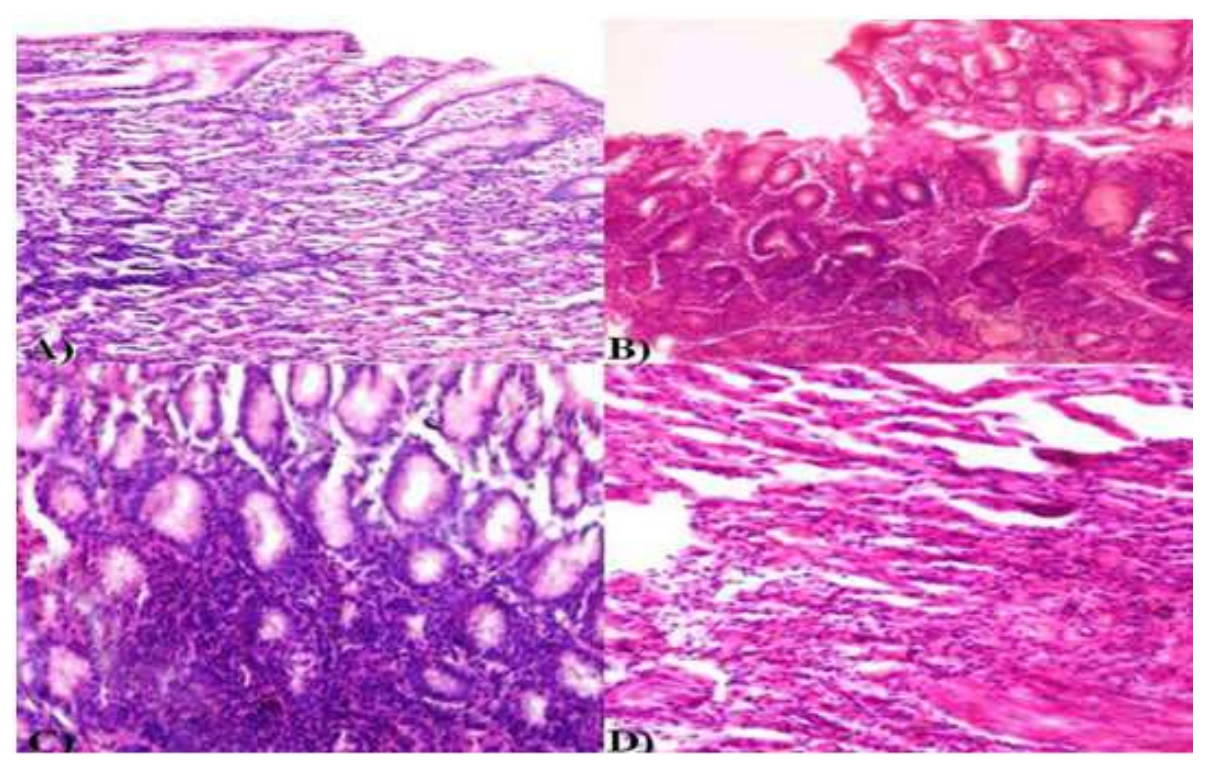

Figure 1: A) Photomicrograph (H\&E, 10x) showing mild chronic body gastritis. B) and C) Photomicrographs (H\&E, $10 \mathrm{x})$ showing moderate and severe chronic antral gastritis respectively. D) Photomicrograph (H\&E, 10x) showing moderately active chronic body gastritis.

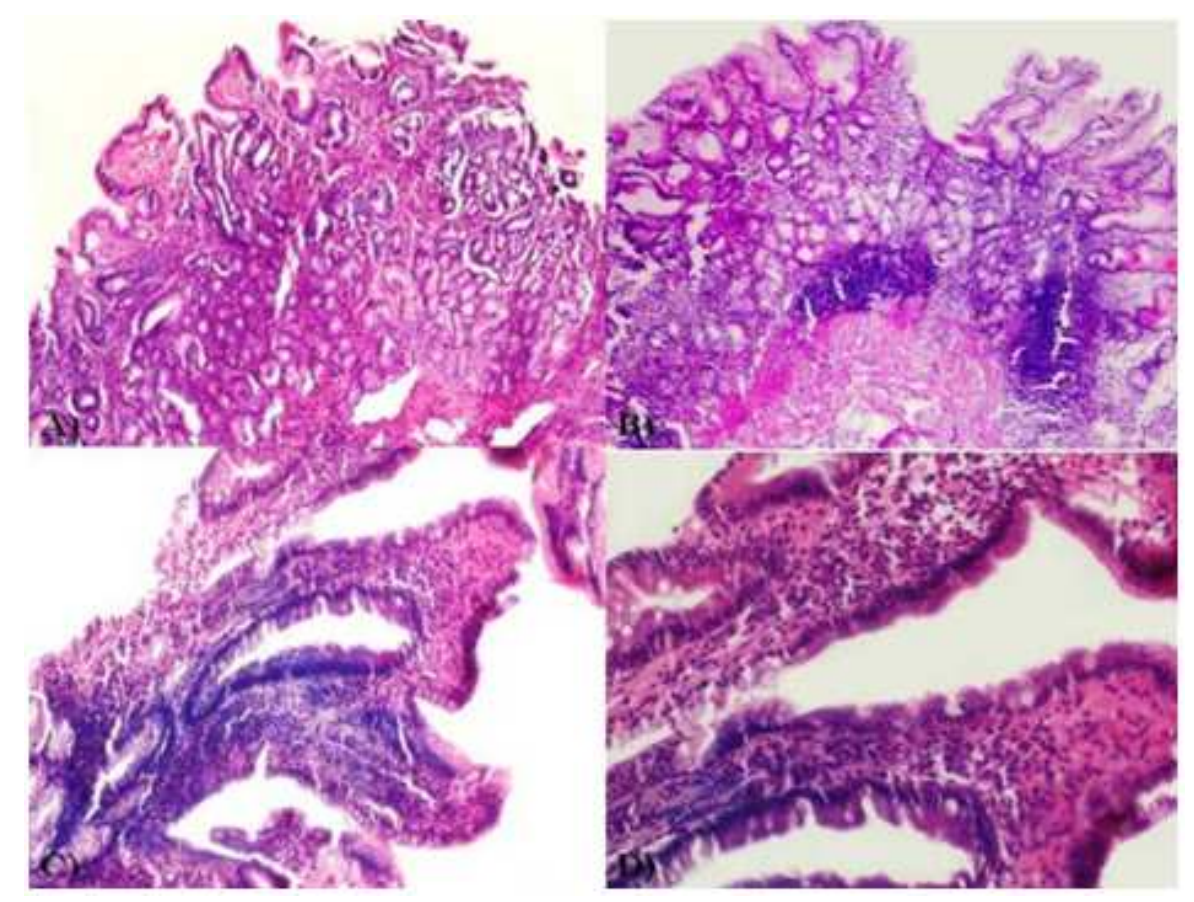

Figure 2: A) and B) Photomicrographs (H\&E, 10x) showing chronic antral gastritis with mild glandular atrophy and presence of lymphoid follicles respectively. C) and D) Photomicrographs C) H\&E, 10x and D) H\&E, 20x showing moderately active chronic antral gastritis with foci of intestinal metaplasia and presence of goblet cells. 


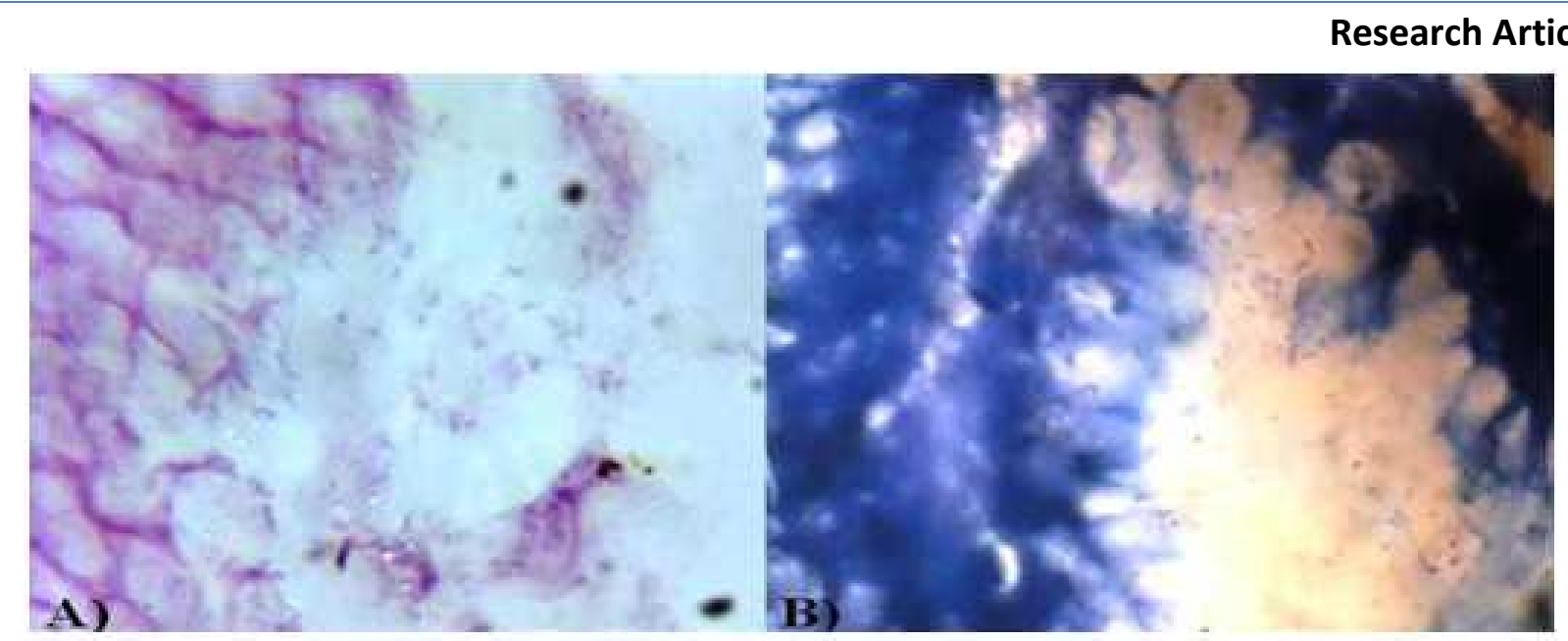

Figure 3: Photomicrographs A) H\&E, 100x and B) Modified Giemsa, 100x showing numerous H. pylori on the surface of gastric mucosa.

$50.56 \%$ cases of chronic gastritis were positive for $\mathrm{H}$. pylori in the present study. The results were similar to previously published studies [15-16]. Association of $\mathrm{H}$. pylori with degree of chronic inflammation, neutrophilic activity, lymphoid aggregates, intestinal metaplasia and atrophy in chronic gastritis was evaluated. $36.36 \%$ cases of chronic gastritis with mild inflammation and $60.53 \%$ cases of chronic gastritis with moderate inflammation were positive for $\mathrm{H}$. pylori. $\mathrm{H}$. pylori were positive in $85.71 \%$ cases of chronic gastritis with severe inflammation similar to Misra V et al. [17].

A significant association was seen between degree of chronic inflammation and $\mathrm{H}$. pylori infection $(\mathrm{p}<0.05)$. Neutrophilic activity is an almost universal phenomenon in $\mathrm{H}$. pylori gastritis. Biopsy specimens contain neutrophils in virtually all cases of $\mathrm{H}$. pylori positive gastritis. Neutrophils are a very sensitive indicator for the presence or absence of $\mathrm{H}$. pylori and disappear within days of cure of infection [18].

In the present study, 35 cases of chronic gastritis showed activity. $85.71 \%$ of these cases were positive for $H$. pylori and the association was statistically significant. Kalebi A et al. [19] in their study on superficial gastritis showed H. pylori infection in $91 \%$ of cases with neutrophilic infiltration.

Shafii M et al. [20] in their study concluded that activity had statistically significant association with $\mathrm{H}$. pylori. 26 cases of chronic gastritis showed lymphoid aggregates. $76.92 \%$ of these cases were positive for $\mathrm{H}$. pylori and the association was statistically significant $(\mathrm{p}<0.05)$. Genta RM et al. [21] found $91.8 \%$ prevalence of lymphoid follicles in patients with $H$. pylori infection. Chen XY et al. [11] concluded that lymphoid follicles and aggregates were found in the gastric antral mucosa of $76.0 \%$ patients with various $H$. pylori associated gastric diseases. 7 cases of chronic gastritis showed intestinal metaplasia.

Only $28.57 \%$ of these cases were positive for $\mathrm{H}$. pylori and the association was statistically insignificant ( $p>0.05$ ). Mysorekar VV et al. [22] observed significant association between $H$. pylori colonization and intestinal metaplasia in acid peptic disease patients. In the latter study, apart from Giemsa staining, Rapid Urease Test was done for $H$. pylori detection. The discrepancy in the present study may be due to inadequate sampling.

Also study by Craanen ME et al. [23] has shown that yield for H. pylori infection is reduced when intestinal metaplasia is present. 11 cases of chronic gastritis showed atrophy. $63.64 \%$ of these cases were positive for $H$. pylori. However, the association in the present study was not statistically significant $(\mathrm{p}>0.05)$.

Thus we conclude that histopathology should be performed in all cases of chronic gastritis. The updated Sydney classification provides an objective histological evaluation of chronic gastritis.

Also the grade of chronic inflammation, neutrophilic activity and lymphoid follicles are significantly associated with $\mathrm{H}$. pylori infection. So search for $\mathrm{H}$. pylori should be initiated if neutrophils and lymphoid follicles are seen in the antral biopsies.

The detection of $\mathrm{H}$. pylori can help us plan treatment strategies to reduce the menace of this organism. 


\section{Acknowledgements: Nil}

Conflicts of interest: The authors declare that there are no conflicts of interest

Grants: Nil

\section{References:}

1. Barr H. Endoscopic screening for upper gastrointestinal malignancy. In: Westby D, Lombard M editors. Therapeutic Gastrointestinal Endoscopy. UK: Martin Dunitz Ltd; 2002. p.54-56.

2. Versalovic J. Helicobacter pylori. Pathology and diagnostic strategies. Am J Clin Pathol. 2003 Mar;119(3):403-12.

3. Locke CR 3rd, Talley NJ, Nelson DK, Haruma K, Weaver AL, Zinsmeister AR, Melton LJ 3rd. Helicobacter pylori and dyspepsia: a population-based study of the organism and host. Am J Gastroenterol. 2000 Aug;95(8):1906-13.

4. Kate V, Ananthakrishnan N, Badrinath S, Ratnakar C. Prevalence of Helicobacter pylori infection in disorders of the upper gastrointestinal tract in south India. Natl Med J India. 1998 Jan-Feb;11(1):5-8.

5. Langenberg ML, Tytgat GNJ, Schipper MEI, Rietra PJGM, Zanen HC. Campylobacter-like organisms in the stomach of patients and healthy individuals. Lancet. 1984 Jun 16;1(8390):1348-9.

6. Misiewicz JJ. The Sydney System: a new classification of gastritis. Introduction. J Gastroenterol Hepatol. 1991 May-Jun;6(3):207-8.

7. DixonMF, Genta RM, Yardley JH, Correa P. Classification and grading of gastritis. The updated Sydney System. International Workshop on the Histopathology of Gastritis, Houston 1994. Am J Surg Pathol. 1996 Oct;20(10):1161-81.

8. Garg B, Sandhu V, Sood N, Sood A, Malhotra V. Histopathological analysis of chronic gastritis and correlation of pathological features with each other and with endoscopic findings. Pol J Pathol. 2012 Nov;63(3):172-8.

9. Bodger K, Crabtree JE. Helicobacter pylori and gastric inflammation. Br Med Bull. 1998;54(1):139-50.
Research Article

10. Price AB. The Sydney System: histological division. J Gastroenterol Hepatol. 1991 MayJun;6(3):209-22.

11. Chen XY, Liu WZ, Shi Y, Zhang DZ, Xiao SD, Tytgat GNJ. Helicobacter pylori associated gastric diseases and lymphoid tissue hyperplasia in gastric antral mucosa. J Clin Pathol. 2002 Feb;55(2):133-7.

12. Manxhuka-Kerliu S, Telaku S, Devolli-Disha E, Ahmetaj H, Sahatciu-Meka V, Kerliu A, Loxha S, Shahini L, Gashi G, Podrimaj A. Helicobacter pylori gastritis updated Sydney classification applied in our material. Prilozi. 2009 Jul;30(1):45-60.

13. Atisook K, Kachinthorn U, Luengrojanakul P, Tanwandee T, Pakdirat P, Puapairoj A. Histology of gastritis and Helicobacter pylori infection in Thailand: a nationwide study of 3776 cases. Helicobacter. 2003 Apr;8(2):132-141.

14. Dhakhwa R, Acharya IL, Shrestha HG, Joshi DM, Lama S, Lakhey M. Histopathologic Study of Chronic Antral Gastritis. J Nepal Health Res Counc. 2012 Jan;10(20):57-60.

15. Christopher JA, Abiodun OJ, Olawale OS, Abideen OO, Adegboyega A. Prevalence of helicobacter pylori among Nigerian patients with dyspepsia in Ibadan. Pan Afr Med J. 2011;6(18):1-8.

16. Satoskar A, Vora IM. Incidence of Helicobacter pylori associated gastritis in the urban population from India. Trop Geogr Med. 1994;46(3):167-8.

17. Misra V, Misra SP, Singh MK, Singh PA, Dwivedi M. Prevalence of H.pylori in patients with gastric cancer. Indian J Pathol Microbiol.2007Oct;50(4):702-7.

18. Stolte M, Eidt S. Chronic erosions of the antral mucosa: a sequela of Helicobacter pylori-induced gastritis. Z Gastroenterol. 1992 Dec;30(12):846-50.

19. Kalebi A, Rana F, Mwanda W, Lule G, Hale M. Histopathological profile of gastritis in adult patients seen at a referral hospital in Kenya. World $\mathrm{J}$ Gastroenterol. 2007 Aug 14;13(30):4117-21.

20. Shafii M, Nikzad SE, Kasiri H, Naghipour M. Histopathological evaluation of chronic gastritis with and without Helicobacter pylori colonization: a study from Iran. Malays J Pathol. 2008 Jun;30(1):27-30. 
21. Genta RM, Hammer HW. The significance of lymphoid follicles in the interpretation of gastric biopsy specimens. Arch Pathol Lab Med. 1994 July;118(7):740-3.

22. Mysorekar VV, Chitralekha, Dandekar P, Prakash BS. Antral histopathological changes in acid peptic
Research Article

disease associated with Helicobacter pylori. Indian $\mathbf{J}$ Pathol Microbiol. 1999 Oct;42(4):427-34.

23. Craanen ME, Blok P, Dekker W, Ferwerda J, Tytgat GNJ. Subtypes of intestinal metaplasia and Helicobacter pylori. Gut. 1992 May;33(5):597-600.

\section{How to cite this article?}

Poonam Sharma, Kuldeep Kumar Kaul, Manik Mahajan, Vijyant Singh Chandail, Kuldeep Goswami, Puneet Gupta Histopathological Changes in Gastric Mucosal Biopsies in Chronic Gastritis and Correlation of Pathological Features with Helicobacter Pylori Infection. Trop J Path Micro 2015;1(1):8-15.doi: 10.17511/jopm.2015.i01.03 